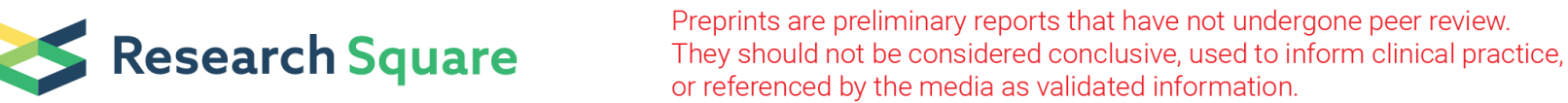

\section{Comparison of survival outcomes of locally advanced cervical cancer by histopathological types in the Surveillance, Epidemiology, and End Results (SEER) database: A propensity score matching study}

Tian Tian

Yunnan Cancer Hospital

Xing Gong

Xiangyang NO 1 people's hospital

\section{Dong Xu Gao}

Yunnan Cancer Hospital

Qing Yan Li

Yunnan Cancer Hospital

Wen Ju

Yunnan Cancer Hospital

Qin Yi Ai ( $\square$ tt1105661762@163.com)

Yunnan Cancer Hospital https://orcid.org/0000-0002-5453-2593

\section{Research Article}

Keywords: SEER, squamous cell carcinoma, adenocarcinoma, cervical cancer, propensity score matching.

Posted Date: May 1st, 2020

DOI: https://doi.org/10.21203/rs.3.rs-18088/v2

License: (c) (i) This work is licensed under a Creative Commons Attribution 4.0 International License. Read Full License

Version of Record: A version of this preprint was published at Infectious Agents and Cancer on May 13th, 2020. See the published version at https://doi.org/10.1186/s13027-020-00299-3. 


\section{Abstract}

Background: There has been limited research on the comparison of squamous cell carcinoma (SCC) and adenocarcinoma (AC) of cervical cancer and that lack of information may have significant bearing on the treatment of patients. We compared survival outcomes between squamous cell carcinoma and adenocarcinoma in locally advanced cervical cancer patients and examined factors related to the prognosis of cervical cancer.

Methods: We identified 4,131 patients with stage IB2-XA cervical cancer patients diagnosed between 2010 and 2015 by using the Surveillance, Epidemiology, and End Results (SEER) database. Variables related to the prognosis of cervical cancer were compared using both univariate and multivariate Cox models and log-rank method before and after propensity score matching. We compared the efficacy of radiotherapy alone to radiotherapy combined with chemotherapy or/and surgery in overall survival of SCC and AC.

Results: Our sample included 3,385 patients with SCC (81.9\%) and 746 patients with AC (18.1\%). The 5year overall survival on comparing the squamous cell carcinoma group and adenocarcinoma group was not significant $(P>0.05)$. Using propensity score matching, 676 pairs of patients were selected. The 5-year overall survival of matched patients did not differ significantly $(P>0.05)$. Histology was not independently associated with overall survival in multivariate Cox model $(P>0.05)$. Factors affecting overall survival included FIGO stage IVA $(P<0.05)$, chemotherapy $(P<0.05)$, and external radiation combined with brachytherapy $(P<0.05)$. Patients with SCC that were treated with radiation alone had significantly worse OS than AC patients receiving radiation only $(P<0.05)$.

Conclusions: The OS in AC of the cervix is similar to that SCC in when treated with radiotherapy combined with chemotherapy and/or surgery but better when treated with radiation alone.

\section{Background}

Cervical cancer is one of the common cancers in women worldwide. According to the World Health Organization, the incidence of cervical cancer ranks first in 28 countries and it is the leading cause of female deaths in 42 countries and it is estimated that 570,000 new cases and 311,000 deaths may occur worldwide in 2019[1]. In China, cervical cancer ranked $8^{\text {th }}$ among the top 10 malignant tumors in 2015, accounting for $2.83 \%$ of all cancers. The incidence of cervical cancer in rural areas is higher than that in cities (6.34\% and $2.68 \%$, respectively) and the average age of onset of cervical cancer is 51 years, primarily in the 40-50 years age range. Cervical cancer rarely occurs before 20 years of age[2].

Cervical cancer includes squamous cell carcinoma (SCC), adenocarcinoma (AC), adenosquamous carcinoma (ASC), neuroendocrine cancer, undifferentiated cancer, and other pathological types. SCC accounts for approximately $70 \%$ and $\mathrm{AC}$ accounts for approximately $25 \%$ cases[3]. High-risk human papilloma virus (HPV) is a significant risk factor for cervical cancer. At present, more than 100 different subtypes of HPV have been found and 54 types able to infect the reproductive tract mucosa. High-risk subtypes include HPV16, 18, 31, 33, 35, 39, and 45. HPV16 and 18 subtypes are most closely related to 
cervical cancer[4]. In recent years, HPV vaccines and screenings have reduced the incidence of cervical cancer in developed countries. However, the age-adjusted incidence rates of AC increased by $0.5 \%$ to $3 \%$ per annum in Europe[5]. It is still controversial as to whether the pathological types of cervical cancer have an impact on the prognosis of patients. Some studies have shown that SCC and AC have the same overall survival (OS)[6,7], while some data suggest that patients with $A C$ of the cervix had poorer OS and disease-free survival (DFS) than patients with SCC [3,8-10].

In the current National Comprehensive Cancer Network (NCCN) guidelines, the standard treatment methods revealed no differences between SCC and AC of cervical cancer. However, the prognosis and clinical characteristics of SCC cervical cancer differs from that of AC cervical cancer. It has been reported that patients with $\mathrm{AC}$ tend to be younger and Caucasian, and they are more commonly diagnosed in the early stages of disease[11].

Some studies have shown that, when compared with radiotherapy alone, concurrent radiotherapy combined with platinum-based chemotherapy can improve survival[12-17]. Since 1999, concurrent chemoradiotherapy has become the standard treatment approach for locally advanced cervical cancer regardless of the histological subtype of the disease. In recent years, some studies have suggested that total hysterectomy after neoadjuvant chemotherapy can improve survival outcomes of cervical cancer[18,19]. This may be because neoadjuvant chemotherapy has the potential to eradicate micrometastases and could reduce systemic failures, in addition to facilitating local control by surgical resection. However, other studies have shown that the effect of neoadjuvant chemotherapy plus surgery does not show superiority compared to concurrent chemoradiotherapy[20,21].

Therefore, we conducted this retrospectively study to analyze the data of patients with cervical cancer in Surveillance, Epidemiology and End Results (SEER) database to compare the survival outcomes of patients with SCC and those with AC among locally advanced cervical cancer patients as well as factors that are related to the prognosis of cervical cancer.

\section{Methods}

\section{Patients}

Information on patients diagnosed with cervical cancer between 2010 and 2015 was extracted from the SEER-18 Regs Custom database using SEER*Stat software, version 8.3.6. We limited our sample to the period 2010-2015, as the information about some variables only are available from 2010 . We included cervical cancer patients in our study using the following parameters: only one primary malignancy; International Federation of Gynecology and Obstetrics (FIGO,2009 version) stages IB2 to IVA; pathological biopsy confirmed SCC and AC; no distant metastases; aged 20 to 69 years; active follow-up with complete date; and complete clinicopathological information. Since the patient information in the SEER database is deidentified and publicly available, our study was exempt from Institutional Review Board approval. This study was conducted in concordance with the Helsinki Declaration. 
Variables for each patient included: race, age, TNM stage, histology grade, T stage, $\mathrm{N}$ stage, pathological subtype, treatment strategy, survival time, and vital status. We restaged TNM stage according to the FIGO classification (2009 version). American Joint Committee on Cancer 7th edition (AJCC7) provided updated guidelines on the

grading of cervical cancer. Patients were treated either with radiation alone, radiotherapy combined with chemotherapy, and/or surgery. Radiotherapy primarily included external radiation, brachytherapy, or external radiation combined with brachytherapy. The primary endpoint of this study was OS.

\section{Statistics Analyses}

The baseline characteristics between cervical cancer patients in the AC and SCC groups were compared with chi-square $\left(\chi^{2}\right)$ or continuity correction tests. A Cox proportional hazards model was used to perform univariate and multivariate analyses of the various factors affecting OS. As the baseline characteristics were different between two groups, propensity score matching (PSM) was performed with a ratio of 1:1. The matching covariates included race, age, TNM stage, histology grade, radiation sequence with surgery, radiotherapy and chemotherapy. Comparisons between the SCC and AC groups was evaluated by a twoside log-rank test before and after matching and OS was estimated using the Kaplan-Meier method. All analyses were performed using R statistical software (version 3.6.1, package includes survminer, rms, foreign, tableone, broom, matchlt, R Foundation) for statistical analysis. Hazard ratio (HR) and 95\% confidence intervals (Cls) were compared between two groups. Two-sided $p<0.05$ was defined as statistically significant.

\section{Results And Conclusions}

\section{Patient Baseline Characteristics}

There were 4,131 eligible patients who were diagnosed with stage IB2 to IVA cervical cancer between 2010 to 2015 , including 3,385 (81.9\%) patients in the SCC group and $746(18.1 \%)$ patients in the AC group. The detailed characteristics of patients in the SCC and AC groups before and after propensity score matching are shown in Table 1 . There were significantly more patients between the ages 40 and 49 in the AC group than in the SCC group (28.5\% in the SCC group and $33.9 \%$ in the AC group, $P=0.02)$. The SCC and AC groups differed significantly when comparing the distribution of well differentiated (grade I) and undifferentiated (grade IV) cancer (4.2\% and 1.5\% in SCC group, $18.5 \%$ and $4.0 \%$ in AC group, $\mathrm{P}<0.001)$. There were more patients with FIGO stages IIB - IVA in the SCC group (82.8\% in SCC group, $71.9 \%$ in AC group, $\mathrm{P}<0.001)$. The median survival time of patients in the SCC and AC groups was 33.6 (range, 0-83 months) and 35.8 months (range, 0-83 months), respectively ( $P=0.013)$.

\section{Survivals of patients in SCC and AC groups}

To balance the baseline characteristics, 676 cervical patients with $A C$ were matched 1:1 to patients with SCC. The baseline characteristics were similar between two groups after matching (Table 1). The OS 
curves of patients with SCC and AC are shown in Figure 1. The 5-year OS of patients in the SCC and AC groups were $16 \%$ and $18 \%(P=0.67)$ before matching and were $16 \%$ and $17 \%$ after matching $(P=0.53)$.

\section{Univariate and multivariate analysis}

In Table 2, we present the results of the univariate analysis showing that histology was not a significant factor for OS. The univariate COX hazard ratio (HR) was 1.02 (95\% confidence interval (Cl) 0.93-1.12, $\mathrm{P}=0.69)$. As shown in Table 2, the primary univariate factors affecting OS were: FIGO stage IVA (HR=0.74, $95 \% \mathrm{Cl} 0.57-0.98, p=0.03$ ), chemotherapy (HR 0.85, 95\% $\mathrm{Cl} 0.75-0.97, p=0.01)$, race (HR=1.20, 95\% Cl 1.03$1.39, \mathrm{p}=0.02)$ and external radiation combined with brachytherapy ( $\mathrm{HR} 0.93,95 \% \mathrm{Cl} 0.86-1.00, \mathrm{p}=0.06)$. Multivariate analysis found the same associated factors (Figure 1).

\section{Subgroup analysis}

For these analyses, we stratified patients by treatment and performed 1:1 matching on pathology. The detailed characteristics of subgroups after propensity score matching are shown in Table 3 and Table 4 .After matching, 15 cervical cancer patients with AC were matched with 15 patients with SCC (Figure 2A) in the radiation only group. We showed that the OS of patients with SCC was significantly worse than that of patients with $A C(P=0.015)$. In the radiation combined with chemotherapy subgroup, we defined 282 matched pairs. The OS of patients receiving radiation combined with chemotherapy did not differ significantly by pathology $(\mathrm{P}=0.62)$ (Figure $2 \mathrm{~B}$ ). Figure $2 \mathrm{C}$ shows the OS comparing 49 matched subgroups treated with radiotherapy combined with surgery. Within this subgroup, the median survival time was shorter for AC patients, although these results were not statistically significant. Finally, we analyzed radiotherapy combined with chemotherapy plus surgery in 305 pairs and found that the OS of SCC and AC was very similar ( $P=0.92)$ (Figure 2D).

\section{Discussion}

Adenocarcinoma is a small pathological subtype in cervical cancer. In recent years, while the incidence of cervical cancer has generally declined[22], the incidence of AC has increased[5]. However, using the same treatment as for SCC may not be appropriate for AC patients[23]According to NCCN guidelines, the standard treatment for locally advanced cervical cancer is radiotherapy and concomitant chemotherapy using cisplatin, a protocol that was developed in SCC patients. As a result, there has been increasing interest in determining optimum treatments for AC. There are still considerable debates about the prognostic patterns between patients of $A C$ and SCC as well as the proper treatment based on subgroup.. ASC and AC cancers together represented $21.3 \%, 22.9 \%$ and $24.1 \%$ of cases for the years $1988-1993$, 1994-1999 and 2000-2005, respectively[10] .A study based on the SEER database by Vijaya Galic, et al. showed that the incidence of AC and ASC was increasing 1-2\% every 6 years[9].

With this increasing pattern, researchers are increasingly interested in cervical AC. The literature shows that there is still a significant debate regarding the prognosis of patients with AC and SCC of the cervix. Some studies have shown that SCC of the cervix has a similar OS as that of AC[6]. Other studies have 
shown that AC is less sensitive to radiotherapy than SCC of the cervix, especially in patients with poor prognostic factors[8]. Therefore, in this study, we collected cervical cancer data from the SEER database to identify predictive factors associated with cervical cancer, and survival outcomes in patients with AC and SCC.

In 2011, a previous study by Katanyoo, et al. included a total of 423 patients with stages IIB-IVA and showed that the 5-year OS rates of AC and SCC were $59.9 \%$ and $61.7 \%(p=0.191)$, respectively. When all prognostic factors were adjusted, clinical staging was the only factor that influenced OS[6]. In 2014, Rose, et al. performed a retrospective analysis of 1,671 patients with cervical cancer and suggested that when treated with radiotherapy alone, the OS of AC was worse than that of SCC. When the treatment was radiotherapy and concomitant platinum-based chemotherapy, the OS of patients is similar[11]. In our study, we saw similar patterns. However, in 2018, Hu, et al. compared the treatment outcomes between SCC and AC of the cervix after definitive radiotherapy or concurrent chemoradiotherapy and showed that, when compared with SCC of the cervix, AC affected younger women, was more aggressive, and had more para-aortic metastatic lymph nodes. The 3-year disease-free survival, OS, local control rate, and distant control rate were worse for AC when compared to SCC[3]. In the same year, a propensity score matching study by Yin, et al. enrolled 181 locally advanced cervical cancer patients who were treated with intensity modulated radiotherapy/volumetric modulated arc therapy and concurrent chemotherapy. The results showed that after a 1:1 ratio PSM, the 5-year OS, DFS, locoregional failure-free survival, and distant metastasis-free survival in the locally advanced cervical cancer of AC were $46.0 \%, 43.3 \%, 70.0 \%$, and $45.4 \%$, respectively. These results were significantly lower than the corresponding rates of $90.0 \%, 75.8 \%$, $96.6 \%$, and $78.8 \%$ in the matched locally advanced cervical cancer patients of SCC, respectively $(p<0.05)$ [24]. These studies showed a lower OS of AC in cervical cancer.

However, in the present study, we found that histology is not an independent factor of OS. Before PSM, the 3.5-year OS rates in the AC group were $44 \%$ and $18 \%$, and the rates were $39 \%$ and $16 \%$ in the SCC group, respectively $(p=0.67)$. After PSM, the 3 -year and 5 -year OS of the AC group was $43 \%$ and $17 \%$, compared to $40 \%$ and $16 \%$ in the SCC group ( $P=0.53$ ). There was no significant difference in OS between AC group and SCC group, regardless of matching status, leading to different conclusions from the previous studies. When comparing these studies, we did not exclude the impact of different treatments on the prognosis of the two pathological types. To make the results stronger, we divided the treatments into four groups and analyzed the difference between the AC and SCC groups.

In the subgroup analysis, when treated with radiotherapy alone, we found that the OS of patients with SCC was worse than that of patients with $A C(P=0.015)$, in contrast with other studies. The number of people in the analysis was small and the power to detect the difference between AC and SCC may have been too low. When we compared the treated with radiotherapy combined with chemotherapy or radiotherapy combined with chemotherapy plus surgery, the OS of patients with SCC and AC was similar $(P=0.62, P=0.92)$. When treated with radiotherapy combined with surgery, the median survival time and the 3-year and 5-year OS of patients with AC was worse than patients with SCC. However there was no significant difference between two groups $(P=0.71)$. In univariable and multivariable analysis, the factors 
which had the strongest association with survival outcomes was FIGO stage, chemotherapy and external radiation combined with brachytherapy. The difference of study period, number of patients, criteria of enrolled patients, statistical methods and treatment modalities may help us understand the difference of our results when compared to the literature.

This study has some certain limitations. First, we used retrospective studies and we may have unintentional selectivity bias. Second, because the SEER database only recorded the sequence of radiotherapy and surgery, it did not record the sequence of surgery and chemotherapy, and we could not judge whether neoadjuvant therapy or adjuvant therapy is used in the treatment of cervical cancer patients. There was no recorded objective response time and disease-free survival time after treatment; therefore, we could not compare the difference between SCC and AC. In the future, we may need prospective clinical studies to confirm our conclusions.

\section{Conclusion}

Compared with SCC of the cervix, AC has similar OS when treated with radiotherapy combined with chemotherapy and/or surgery but with better OS when treated with radiation alone. Histology is not an independent factor of OS. The factors affecting the prognosis of cervical cancer are the FIGO stage, chemotherapy, race and external radiation combined with brachytherapy.

\section{Declarations}

\section{Ethics approval and consent to participate]}

Informed consent was obtained from all individual participants included in the study. Since the patient information in the SEER database is deidentified and publicly available, our study was exempt from Institutional Review Board approval. This study was conducted in concordance with the Helsinki Declaration.

\section{Consent for publish}

Not applicable

\section{Availability of data and materials:}

The datasets generated and/or analysed during the current study are available in the Surveillance, Epidemiology, and End Results (SEER) database repository, https://seer.cancer.gov.

\section{Competing interests}

The authors declare that they have no competing interests.

\section{Funding}


None

\section{Authors' contributions}

Conception and design: Tian Tian and Xing Gong; (II) Administrative support: Yiqin Ai ; (III) Provision of study materials or patients: Tian Tian and Xing Gong; (IV) Collection and assembly of data: Tian Tian and Xing Gong; (V) Data analysis and interpretation: All authors; (VI) Manuscript writing: All authors; (VII) Final approval of manuscript: All authors.

\section{Acknowledgements}

Thanks for The Third Affiliated Hospital of Kunming Medical University supporting the writing of this manuscript.

\section{References}

1. Siegel RL, Miller KD. Cancer Statistics , 2019. CA Cancer J Clin. 2019;69:7-34.

2. Chen W, Zheng R, Baade PD, Zhang S, Zeng H. Cancer Statistics in China, 2015. CA Cancer J Clin. 2016;66:115-32.

3. Hu K, Wang W, Liu X, Meng Q, Zhang F. Comparison of treatment outcomes between squamous cell carcinoma and adenocarcinoma of cervix after definitive radiotherapy or concurrent chemoradiotherapy. Radiat Oncol. 2018;13:1-7.

4. Huh WK, Joura EA, Giuliano AR, Iversen OE, de Andrade RP, Ault KA, et al. Final efficacy, immunogenicity, and safety analyses of a nine-valent human papillomavirus vaccine in women aged 16-26 years: a randomised, double-blind trial. Lancet [Internet]. Elsevier Ltd; 2017;390:2143-59. Available from: http://dx.doi.org/10.1016/S0140-6736(17)31821-4

5. Bray F, Carstensen B, Møller H, Zappa M, Žakelj MP, Lawrence G, et al. Incidence trends of adenocarcinoma of the cervix in 13 European countries. Cancer Epidemiol Biomarkers Prev. 2005;14:2191-9.

6. Katanyoo K, Sanguanrungsirikul S, Manusirivithaya S. Comparison of treatment outcomes between squamous cell carcinoma and adenocarcinoma in locally advanced cervical cancer. Gynecol Oncol [Internet]. Elsevier Inc.; 2012;125:292-6. Available from: http://dx.doi.org/10.1016/j.ygyno.2012.01.034

7. Thomas GM. Locally advanced adenocarcinoma and adenosquamous carcinomas of the cervix compared to squamous cell carcinomas of the cervix in Gynecologic Oncology Group trials of cisplatin-based chemoradiation. Gynecol Oncol. 2015;135:208-12.

8. Huang YT, Wang CC, Tsai CS, Lai CH, Chang TC, Chou HH, et al. Long-term outcome and prognostic factors for adenocarcinoma/adenosquamous carcinoma of cervix after definitive radiotherapy. Int $\mathrm{J}$ Radiat Oncol Biol Phys. 2011;80:429-36. 
9. Chen JLY, Huang CY, Huang Y Sen, Chen RJ, Wang CW, Chen YH, et al. Differential clinical characteristics, treatment response and prognosis of locally advanced adenocarcinoma/adenosquamous carcinoma and squamous cell carcinoma of cervix treated with definitive radiotherapy. Acta Obstet Gynecol Scand. 2014;93:661-8.

10. Galic V, Herzog TJ, Lewin SN, Neugut Al, Burke WM, Lu Y, et al. Prognostic significance of adenocarcinoma histology in women with cervical cancer. Gynecol Oncol [Internet]. Elsevier Inc; 2012;125:287-91. Available from: http://dx.doi.org/10.1016/j.ygyno.2012.01.012

11. Rose PG, Java JJ, Whitney CW, Stehman FB, Lanciano R, Thomas GM. Locally advanced adenocarcinoma and adenosquamous carcinomas of the cervix compared to squamous cell carcinomas of the cervix in Gynecologic Oncology Group trials of cisplatin-based chemoradiation. Gynecol Oncol [Internet]. Elsevier B.V.; 2014;135:208-12. Available from: http://dx.doi.org/10.1016/j.ygyno.2014.08.018

12. Whitney CW, Sause W, Bundy BN, Malfetano JH, Hannigan E V., Fowler WC, et al. Randomized comparison of fluorouracil plus cisplatin versus hydroxyurea as an adjunct to radiation therapy in stage IIB-IVA carcinoma of the cervix with negative para-aortic lymph nodes: A Gynecologic Oncology Group and Southwest Oncology Group Study. J Clin Oncol. 1999;17:1339-48.

13. Rose PG, Bundy BN, Watkins EB囚Thigpen JT, Deppe G M, Aiman MA, Clarke-Pearson DL IS. Concurrent Cisplatin-based Radiotherapy and Chemotherapy for Locally Aavanced Cervical Cancer. N Engl J Med. 1999;340:1144-53.

14. Keys HM, Bundy BN, Stehman FB, Muderspach LI, Chafe WE, Suggs CL, Walker JL GD. Cisplatin, Radiation, and Adjuvant Hysterectomy Compared with Radiation and Adjuvant Hysterectomy for Bulky Stage IB Cervical Carcinoma. N Engl J Med. 1999;341:708-708.

15. Peters WA, Liu PY, Barrett RJ, Stock RJ, Monk BJ, Berek JS, et al. Concurrent chemotherapy and pelvic radiation therapy compared with pelvic radiation therapy alone as adjuvant therapy after radical surgery in high-risk early-stage cancer of the cervix. J Clin Oncol. 2000;18:1606-13.

16. Morris M, Eifel PJ, Lu J, Grigsby PW, Levenback C, Stevens RE, et al. Pelvic radiation with concurrent chemotherapy compared with pelvic and para-aortic radiation for high-risk cervical cancer. $\mathrm{N}$ Engl $\mathrm{J}$ Med. 1999;340:1137-43.

17. Eifel PJ, Winter K, Morris M, Levenback C, Grigsby PW, Cooper J, et al. Pelvic irradiation with concurrent chemotherapy versus pelvic and para-aortic irradiation for high-risk cervical cancer: An update of Radiation Therapy Oncology Group Trial (RTOG) 90-01. J Clin Oncol. 2004;22:872-80.

18. Chen H, Liang C, Zhang L, Huang S, Wu X. Clinical efficacy of modified preoperative neoadjuvant chemotherapy in the treatment of locally advanced (stage IB2 to IIB) ervical ancer: randomized study. Gynecol Oncol [Internet]. Elsevier Inc.; 2008;110:308-15. Available from: http://dx.doi.org/10.1016/j.ygyno.2008.05.026

19. Benedetti-Panici P, Greggi S, Colombo A, Amoroso M, Smaniotto D, Giannarelli D, Amunni G, Raspagliesi F, Zola P,et al. Neoadjuvant Chemotherapy and Radical Surgery Versus Exclusive 
Radiotherapy in Locally Advanced Squamous Cell Cervical Cancer: Results From the Italian Multicenter Randomized Study. J Clin Oncol. 2002;20:179-88.

20. Katsumata N, Yoshikawa H, Kobayashi H, Saito T, Kuzuya K, Nakanishi T, et al. Phase III randomised controlled trial of neoadjuvant chemotherapy plus radical surgery vs radical surgery alone for stages IB2, IIA2, and IIB cervical cancer: A Japan Clinical Oncology Group trial (JCOG 0102). Br J Cancer [Internet]. Nature Publishing Group; 2013;108:1957-63. Available from: http://dx.doi.org/10.1038/bjc.2013.179

21. Gupta S, Maheshwari A, Parab P, Mahantshetty U, Hawaldar R, Sastri S, et al. Neoadjuvant Chemotherapy Followed by Radical Surgery Versus Concomitant Chemotherapy and Radiotherapy in Patients With Stage IB2, IIA, or IIB Squamous Cervical Cancer: A Randomized Controlled Trial. J Clin Oncol. 2018;36:1548-55.

22. McGregor S, Saulo D, Brotherton J, Liu B, Phillips S, Skinner SR, et al. Decline in prevalence of human papillomavirus infection following vaccination among Australian Indigenous women, a population at higher risk of cervical cancer: The VIP-I study. Vaccine [Internet]. 2018;36:4311-6. Available from: https://doi.org/10.1016/j.vaccine.2018.05.104

23. Koh W, Abu-rustum NR, Bean S, Bradley K, Campos SM, Cho KR, et al. Cervical Cancer , Version 3 . 2019. 2019;17:64-84.

24. Yin K, Lu C, Lin J, Hsu C, Wang L. ScienceDirect Treatment outcomes of locally advanced cervical cancer by histopathological types in a single institution: A propensity score matching study. $\mathrm{J}$ Formos Med Assoc [Internet]. Elsevier Ltd; 2018; Available from: https://doi.org/10.1016/j.jfma.2018.07.002.

\section{Tables}

Table 1: Characteristics of cervical cancer patients with AC and SCC before and after matching 


\begin{tabular}{|c|c|c|c|c|c|c|}
\hline \multirow{2}{*}{$\begin{array}{l}\text { Characteristics } \\
\text { AC }(n=746)\end{array}$} & \multicolumn{2}{|c|}{ Before matching } & \multicolumn{2}{|c|}{ After matching } & \multirow[b]{2}{*}{$\mathrm{P}$ value } & \multirow[b]{3}{*}{0.872} \\
\hline & $\operatorname{SCC}(n=3385)$ & $\mathrm{P}$ value & $\mathrm{AC}(\mathrm{n}=676)$ & $\operatorname{SCC}(n=676)$ & & \\
\hline age (\%) & & & 0.02 & & & \\
\hline$<40$ & $158(21.2)$ & $840(24.8)$ & & $146(21.6)$ & $143(21.2)$ & \\
\hline $40-49$ & $253(33.9)$ & $965(28.5)$ & & $222(32.8)$ & $236(34.9)$ & \\
\hline $50-59$ & $199(26.7)$ & $947(28.0)$ & & $183(27.1)$ & $179(26.5)$ & \\
\hline $60-69$ & $136(18.2)$ & 633 (18.7) & & $125(18.5)$ & $118(17.5)$ & \\
\hline race (\%) & & & $<0.001$ & & & 0.763 \\
\hline Black & $59(7.9)$ & $568(16.8)$ & & $58(8.6)$ & $62(9.2)$ & \\
\hline White & $596(79.9)$ & $2476(73.1)$ & & $538(79.6)$ & $527(78.0)$ & \\
\hline Other & $91(12.2)$ & $341(10.1)$ & & $80(11.8)$ & $87(12.9)$ & \\
\hline grade (\%) & & & $<0.001$ & & & 0.928 \\
\hline I & $138(18.5)$ & $142(4.2)$ & $80(11.8)$ & $77(11.4)$ & & \\
\hline II & $313(42.0)$ & $1610(47.6)$ & & $306(45.3)$ & 297 (43.9) & \\
\hline III & $265(35.5)$ & $1583(46.8)$ & & $264(39.1)$ & $276(40.8)$ & \\
\hline IV & $30(4.0)$ & $50(1.5)$ & $26(3.8)$ & $26(3.8)$ & & \\
\hline FIGO stage (\%) & & & $<0.001$ & & & 0.923 \\
\hline ab2 & $142(19.0)$ & $366(10.8)$ & & $118(17.5)$ & $121(17.9)$ & \\
\hline Пa1 & $25(3.4)$ & $81(2.4)$ & $21(3.1)$ & $14(2.1)$ & & \\
\hline पa2 & $42(5.6)$ & $135(4.0)$ & $35(5.2)$ & $38(5.6)$ & & \\
\hline $\mathrm{ab}$ & $160(21.4)$ & $732(21.6)$ & & $142(21.0)$ & $143(21.2)$ & \\
\hline पa & $15(2.0)$ & $75(2.2)$ & $14(2.1)$ & $11(1.6)$ & & \\
\hline $\mathrm{ab}$ & $346(46.4)$ & $1837(54.3)$ & & $331(49.0)$ & 333 (49.3) & \\
\hline पa & $16(2.1)$ & $159(4.7)$ & $15(2.2)$ & $16(2.4)$ & & \\
\hline sequence (\%) & & & $<0.001$ & & & 0.974 \\
\hline No surgery & $318(42.6)$ & $2011(59.4)$ & & 308 (45.6) & $302(44.7)$ & \\
\hline RPTS & $55(7.4)$ & $133(3.9)$ & $45(6.7)$ & $48(7.1)$ & & \\
\hline RAS & 365 (48.9) & $1218(36.0)$ & & 315 (46.6) & 317 (46.9) & \\
\hline RBAS & $8(1.1)$ & $23(0.7)$ & $8(1.2)$ & $9(1.3)$ & & \\
\hline
\end{tabular}




\begin{tabular}{|c|c|c|c|c|c|c|}
\hline Beam radiation & $328(44.0)$ & 1487 (43.9) & & $294(43.5)$ & $323(47.8)$ & \\
\hline brachytherapy & $82(11.0)$ & $328(9.7)$ & $70(10.4)$ & $70(10.4)$ & & \\
\hline BRB & $336(45.0)$ & $1570(46.4)$ & & $312(46.2)$ & $283(41.9)$ & \\
\hline Chemotherapy (\%) & & & 0.017 & 0.865 & & \\
\hline Yes & $652(87.4)$ & $3060(90.4)$ & $596(88.2)$ & $599(88.6)$ & & \\
\hline No & $94(12.6)$ & $325(9.6)$ & $80(11.8)$ & $77(11.4)$ & & \\
\hline status (\%) & & & 0.055 & & & \\
\hline alive & $535(71.7)$ & $2303(68.0)$ & & $480(71.0)$ & $486(71.9)$ & 0.763 \\
\hline dead & $211(28.3)$ & $1082(32.0)$ & $196(29.0)$ & $190(28.1)$ & & \\
\hline time (mean (SD)) & $35.8(21.4)$ & $33.6(21.7)$ & 0.013 & $35.0(21.1)$ & $33.7(21.5)$ & 0.269 \\
\hline
\end{tabular}

AC adenocarcinoma, SCC Squamous cell carcinoma, FIGO the International Federation of Gynecology and Obstetrics, No surgery Radiation and/or chemotherapy, RPTS Radiation prior to surgery, RAS Radiation after surgery, RBAS Radiation before and after surgery, BRB Combination of beam with brachytherapy. SD Standard Deviation.

Table 2 Univariate analysis of factors associated with OS 


\begin{tabular}{|c|c|c|}
\hline Variables & Univariate (OS) & \\
\hline HR (95\%CI) & $P$ value & \\
\hline \multicolumn{3}{|l|}{ histology } \\
\hline $\mathrm{AC}$ & 1.00 (reference) & \multirow[b]{2}{*}{0.69} \\
\hline SCC & $1.02(0.93-1.12)$ & \\
\hline \multicolumn{3}{|l|}{ age (\%) } \\
\hline$<40$ & 1.00 (reference) & \multirow[b]{2}{*}{0.61} \\
\hline $40-49$ & $1.03(0.93-1.13)$ & \\
\hline $50-59$ & $0.97(0.88-1.08 \square$ & 0.59 \\
\hline $60-69$ & $1.01(0.90-1.14 \square$ & 0.81 \\
\hline \multicolumn{3}{|l|}{ race (\%) } \\
\hline Black & \multicolumn{2}{|l|}{1.00 (reference) } \\
\hline White & $1.06(0.95-1.18 \square$ & 0.28 \\
\hline Other & $1.20(1.03-1.39 \square$ & 0.02 \\
\hline \multicolumn{3}{|l|}{ grade (\%) } \\
\hline I & 1.00 (reference) & \multirow[b]{2}{*}{0.36} \\
\hline II & $1.07(0.93-1.24 \square$ & \\
\hline III & $1.00(0.86-1.15$ & 0.95 \\
\hline IV & $1.12(0.82-1.53[$ & 0.47 \\
\hline
\end{tabular}

FIGO stage (\%)

\begin{tabular}{ccc}
\hline$\square \mathrm{b} 2$ & 1.00 (reference) & \\
\hline$\square \mathrm{a} 1$ & $1.02(0.81-1.27 \square$ & 0.88 \\
\hline$\square \mathrm{a} 2$ & $1.17(0.96-1.43 \square$ & 0.12 \\
\hline$\square \mathrm{b}$ & $0.98(0.87-1.10 \square$ & 0.72 \\
\hline$\square \mathrm{a}$ & $1.07(0.80-1.42 \square$ & 0.64 \\
\hline$\square \mathrm{b}$ & $1.00(0.90-1.11 \square$ & 0.94 \\
\hline$\square \mathrm{a}$ & $0.74(0.57-0.98 \square$ & 0.03 \\
\hline sequence (\%) & \\
\hline No surgery & 1.00 (reference)
\end{tabular}

Page 13/21 


\begin{tabular}{|c|c|c|}
\hline RPTS & $0.88(0.73-1.05 \square$ & 0.16 \\
\hline RAS & $0.93(0.87-1.01)$ & 0.10 \\
\hline RBAS & $1.11(0.72-1.73)$ & 0.63 \\
\hline \multicolumn{3}{|l|}{ Radiation (\%) } \\
\hline Beam radiation & 1.00 (reference) & \\
\hline brachytherapy & $0.98(0.86-1.11)$ & 0.70 \\
\hline $\mathrm{BRB}$ & $0.93(0.86-1.00)$ & 0.06 \\
\hline \multicolumn{3}{|l|}{ Chemotherapy } \\
\hline Yes & 1.00 (reference) & \\
\hline No & $0.85(0.75-0.97)$ & 0.01 \\
\hline
\end{tabular}

AC adenocarcinoma, SCC Squamous cell carcinoma, FIGO the International Federation of Gynecology and Obstetrics, No surgery Radiation and/or chemotherapy, RPTS Radiation prior to surgery, RAS Radiation after surgery, RBAS Radiation before and after surgery, BRB Combination of beam with brachytherapy, CI indicates confidence interval, HR hazard ratio.

Table 3 characteristics of radiotherapy alone group and radiotherapy combined with chemotherapy group after matching. 


\begin{tabular}{|c|c|c|c|c|c|c|}
\hline \multirow[t]{2}{*}{ Characteristics } & \multicolumn{2}{|c|}{ Radiotherapy alone } & \multirow[b]{2}{*}{$P$ value } & \multicolumn{2}{|l|}{ CTRT } & \multirow[b]{2}{*}{$P$ value } \\
\hline & $\mathrm{AC}(\mathrm{n}=15)$ & $\operatorname{SCC}(n=15)$ & & $\mathrm{AC}(\mathrm{n}=282)$ & $\operatorname{SCC}(n=282)$ & \\
\hline age $(\%)$ & & & 0.833 & & & 0.901 \\
\hline$<40$ & $2(13.3)$ & $2(13.3)$ & & $41(14.5)$ & $41(14.5)$ & \\
\hline $40-49$ & $5(33.3)$ & $6(40.1)$ & & $98(34.8)$ & $100(35.5)$ & \\
\hline $50-59$ & $4(26.7)$ & $2(13.3)$ & & $79(28.0)$ & $84(29.8)$ & \\
\hline $60-69$ & $4(26.7)$ & $5(33.3)$ & & $64(22.7)$ & $57(20.2)$ & \\
\hline race (\%) & & & 0.648 & & & 0.969 \\
\hline Black & $2(13.3)$ & $4(26.7)$ & & $27(9.6)$ & $27(9.6)$ & \\
\hline White & 13 (86.7) & $11(73.3)$ & & $36(12.8)$ & $38(13.5)$ & \\
\hline Other & $0(0.0)$ & $0(0.0)$ & & $219(77.6)$ & 217 (76.9) & \\
\hline grade (\%) & & & 1.000 & & & 0.991 \\
\hline I & $0(0.0)$ & $0(0.0)$ & & $33(11.7)$ & $34(12.1)$ & \\
\hline II & $4(26.7)$ & $5(33.3)$ & & $116(41.1)$ & $114(40.4)$ & \\
\hline III & $11(73.3)$ & $10(66.7)$ & & $124(44.0)$ & $126(44.7)$ & \\
\hline IV & $0(0.0)$ & $0(0.0)$ & & $9(3.2)$ & $8(2.8)$ & \\
\hline FIGO stage (\%) & & & 0.970 & & & 0.012 \\
\hline $\mathrm{ab} 2$ & $2(13.3)$ & $1(6.7)$ & & $45(16.0)$ & $25(8.9)$ & \\
\hline \a1 & $1(6.7)$ & $1(6.7)$ & & $5(1.8)$ & $5(1.8)$ & \\
\hline \a2 & $0(0.0)$ & $1(6.7)$ & & $11(3.9)$ & $7(2.5)$ & \\
\hline $\mathrm{ab}$ & $2(13.3)$ & $2(13.3)$ & & $77(27.3)$ & $68(24.1)$ & \\
\hline$\square \mathrm{a}$ & $1(6.7)$ & $1(6.7)$ & & $10(3.5)$ & $9(3.2)$ & \\
\hline $\mathrm{ab}$ & 7 (46.7) & 7 (46.7) & & $127(45.0)$ & $146(51.7)$ & \\
\hline$\square \mathrm{a}$ & $2(13.3)$ & $2(13.3)$ & & $7(2.5)$ & $22(7.8)$ & \\
\hline Radiation (\%) & & & 0.766 & & & 0.545 \\
\hline Beam radiation & $11(73.3)$ & 11 (73.3) & & $100(35.5)$ & $91(32.3)$ & \\
\hline
\end{tabular}




\begin{tabular}{|c|c|c|c|c|c|c|}
\hline brachytherapy & $2(13.3)$ & $3(20.0)$ & & $146(51.7)$ & $159(56.4)$ & \\
\hline BRB & $2(13.3)$ & $1(6.7)$ & & $36(12.8)$ & $32(11.3)$ & \\
\hline status (\%) & & & 1.000 & & & 0.542 \\
\hline alive & $9(60.0)$ & $9(60.0)$ & & $181(64.2)$ & $173(61.3)$ & \\
\hline dead & $6(40.0)$ & $6(40.0)$ & & $101(35.8)$ & $109(38.7)$ & \\
\hline time(mean(SD)) & $40.4(32.5)$ & $26.1(18.6)$ & 0.150 & 33.5 (21.6) & $31.8(22.5)$ & 0.353 \\
\hline
\end{tabular}

AC adenocarcinoma, SCC Squamous cell carcinoma, FIGO the International Federation of Gynecology and Obstetrics, BRB Combination of beam with brachytherapy. CTRT radiotherapy combined with chemotherapy, grade I Well differentiated, grade $\square$ Moderately differentiated ,grade $\square$ Poorly differentiated ,grade $\square$ Undifferentiated ;SD Standard Deviation.

Table 4 characteristics of radiotherapy plus surgery group and radiotherapy combined with chemotherapy and surgery group after matching. 


\begin{tabular}{|c|c|c|c|c|c|c|}
\hline \multirow[t]{2}{*}{ Characteristics } & \multicolumn{3}{|c|}{ radiotherapy plus surgery } & \multicolumn{2}{|c|}{ CTRT plus surgery } & \multirow[b]{2}{*}{$P$ value } \\
\hline & $\mathrm{AC}(\mathrm{n}=49)$ & $\operatorname{SCC}(n=49)$ & $\mathrm{P}$ value & $\mathrm{AC}(\mathrm{n}=305)$ & $\operatorname{SCC}(n=305)$ & \\
\hline age (\%) & & & 0.750 & & & 0.291 \\
\hline$<40$ & $9(18.4)$ & $9(18.4)$ & & $84(27.5)$ & $78(25.6)$ & \\
\hline $40-49$ & $17(34.7)$ & $14(28.6)$ & & $101(33.1)$ & $93(30.5)$ & \\
\hline $50-59$ & $16(32.7)$ & $15(30.6)$ & & $74(24.3)$ & $95(31.1)$ & \\
\hline $60-69$ & 7 (14.3) & $11(22.4)$ & & $46(15.1)$ & $39(12.8)$ & \\
\hline race $(\%)$ & & & 1.000 & & & 0.56 \\
\hline Black & $3(6.1)$ & $3(6.1)$ & & $17(5.6)$ & $16(5.2)$ & \\
\hline White & $2(4.1)$ & $2(4.1)$ & & $37(12.1)$ & $29(9.5)$ & \\
\hline Other & $44(89.8)$ & $44(89.8)$ & & 251 (82.3) & $260(85.2)$ & \\
\hline grade (\%) & & & 0.502 & & & 0.927 \\
\hline I & $1(2.0)$ & $1(2.0)$ & & $33(10.8)$ & $35(11.5)$ & \\
\hline II & $30(61.2)$ & $25(51.0)$ & & $156(51.1)$ & $153(50.2)$ & \\
\hline III & $17(34.7)$ & $23(46.9)$ & & $109(35.7)$ & $112(36.7)$ & \\
\hline IV & $1(2.0)$ & $0(0.0)$ & & $7(2.3)$ & $5(1.6)$ & \\
\hline FIGO stage (\%) & & & 0.378 & & & 0.066 \\
\hline $\mathrm{ab} 2$ & $18(36.7)$ & $17(34.7)$ & & $54(17.7)$ & $34(11.1)$ & \\
\hline \a1 & $3(6.1)$ & $0(0.0)$ & & $11(3.6)$ & $7(2.3)$ & \\
\hline \a2 & $4(8.2)$ & $3(6.1)$ & & $19(6.2)$ & $9(3.0)$ & \\
\hline $\mathrm{ab}$ & $5(10.2)$ & $12(24.5)$ & & 57 (18.7) & 60 (19.7) & \\
\hline$\square \mathrm{a}$ & $1(2.0)$ & $1(2.0)$ & & $2(0.7)$ & $2(0.7)$ & \\
\hline $\mathrm{ab}$ & $16(32.7)$ & $15(30.6)$ & & $159(52.1)$ & $190(62.3)$ & \\
\hline$\square \mathrm{a}$ & $2(4.1)$ & $1(2.0)$ & & $3(1.0)$ & $3(1.0)$ & \\
\hline Radiation (\%) & & & 0.659 & & & 0.988 \\
\hline Beam radiation & $34(69.4)$ & $34(69.4)$ & & $145(47.5)$ & $144(47.2)$ & \\
\hline
\end{tabular}




\begin{tabular}{|c|c|c|c|c|c|c|}
\hline brachytherapy & $11(22.4)$ & $13(26.5)$ & & $136(44.6)$ & $136(44.6)$ & \\
\hline $\mathrm{BRB}$ & $4(8.2)$ & $2(4.1)$ & & $24(7.9)$ & $25(8.2)$ & \\
\hline status (\%) & & & 1.000 & & & \\
\hline alive & $40(81.6)$ & $40(81.6)$ & & $234(76.7)$ & $236(77.4)$ & 0.923 \\
\hline dead & $9(18.4)$ & $9(18.4)$ & & $71(23.3)$ & $69(22.6)$ & \\
\hline time (mean (SD)) & $37.9(22.0)$ & $39.4(22.1)$ & 0.749 & $37.3(20.6)$ & $37.4(21.0)$ & 0.939 \\
\hline
\end{tabular}

AC adenocarcinoma, SCC Squamous cell carcinoma, FIGO the International Federation of Gynecology and Obstetrics, BRB Combination of beam with brachytherapy. CTRT radiotherapy combined with chemotherapy, grade I Well

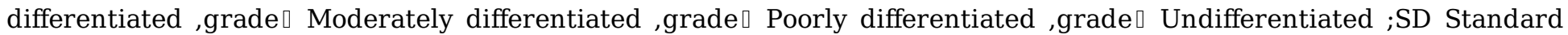
Deviation.

Figures 
Multivariate analysis

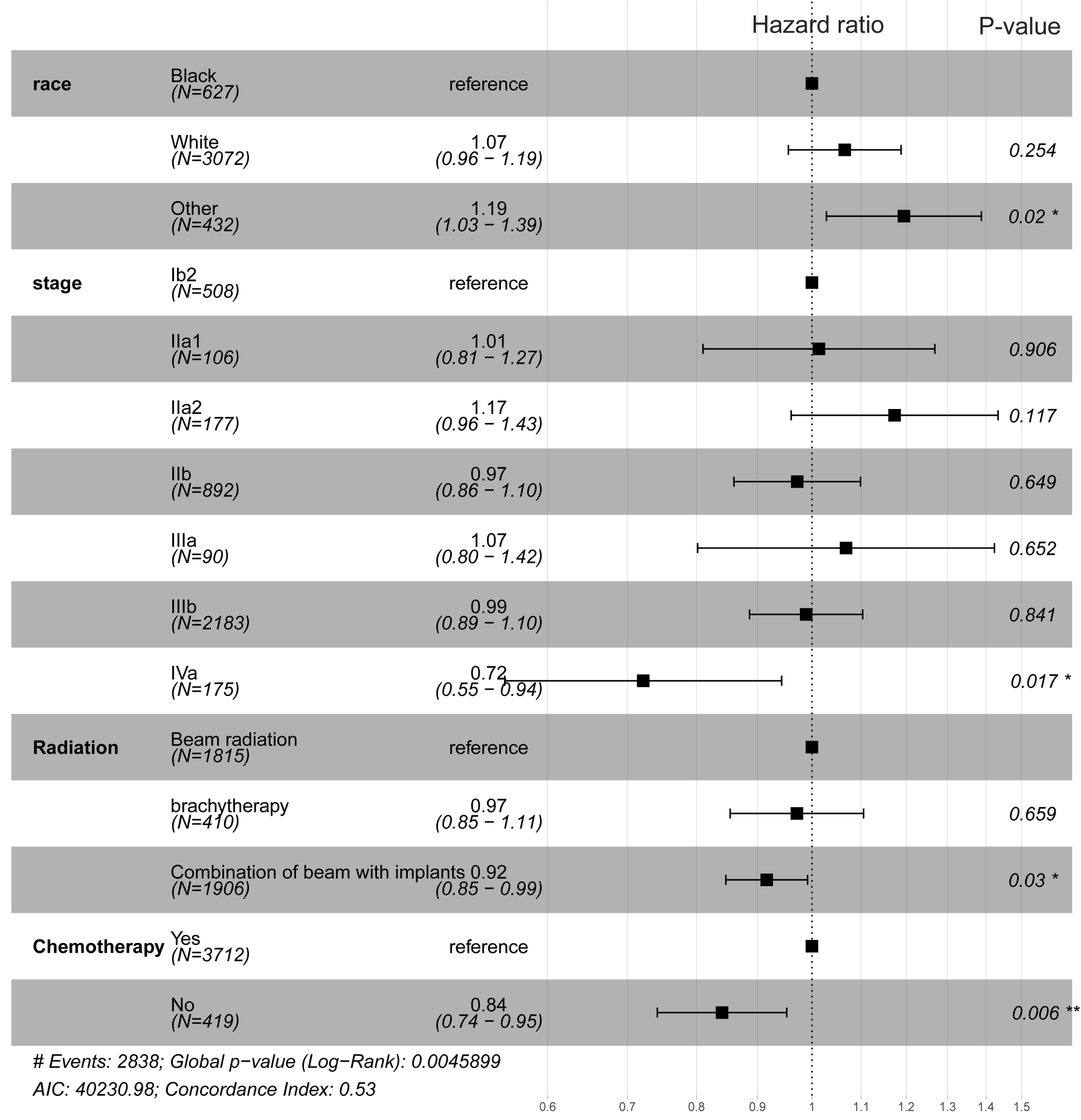

\section{Figure 1}

Univariate analysis of factors associated with OS 

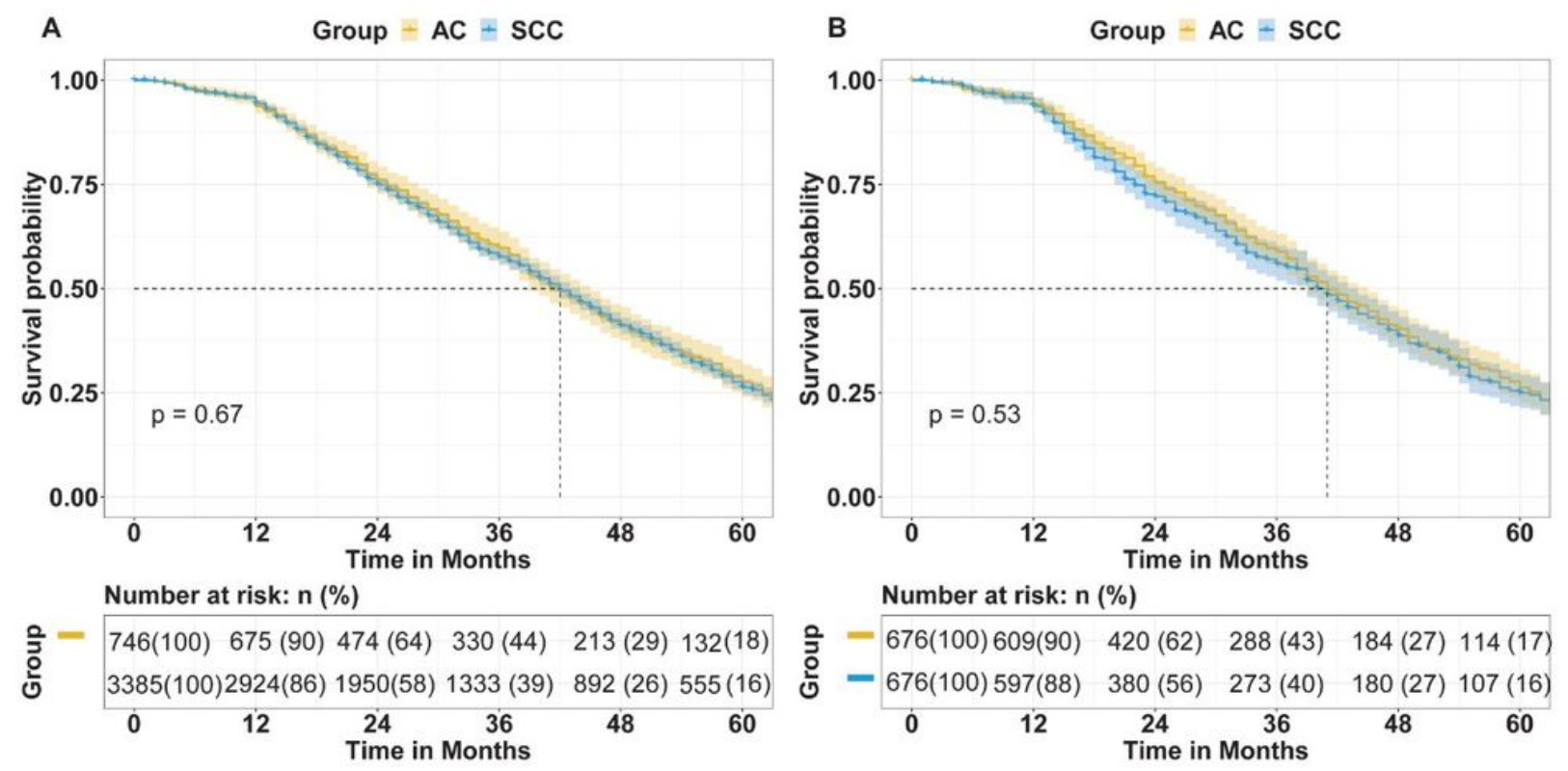

\section{Figure 2}

The overall survival (OS) of patients with squamous cell carcinoma (SCC) and adenocarcinoma (AC) (A) before propensity score matching (PSM) (B) after PSM. 

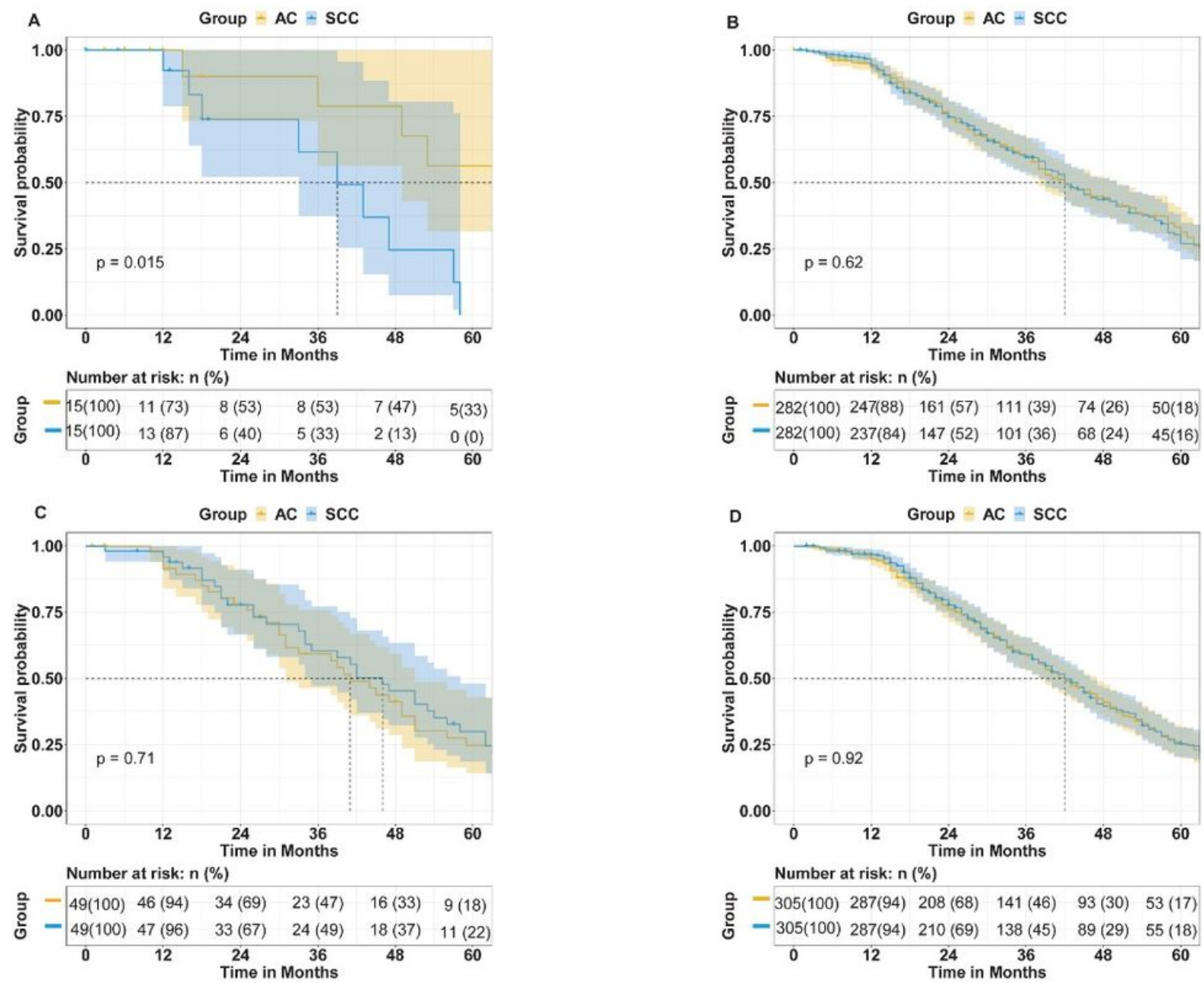

\section{Figure 3}

Treated with radiotherapy alone the overall survival (OS) of patients with squamous cell carcinoma (SCC) and adenocarcinoma (AC) (A); treated with radiotherapy and chemotherapy the OS of patients with SCC and $A C(B)$, treated with radiotherapy and surgery the OS of patients with $S C C$ and $A C(C)$; treated with radiotherapy, surgery and chemotherapy the OS of patients with SCC and $A C(D)$ 